\title{
"Leaning into the Light" \\ A Review of Carina Henriksson's Living Away From Blessings: School Failure as Lived Experience
}

\author{
Patrick Howard, Nova Central School District, \\ Newfoundland \& Labrador, Canada \\ Email: patrickhoward@ncsd.ca
}

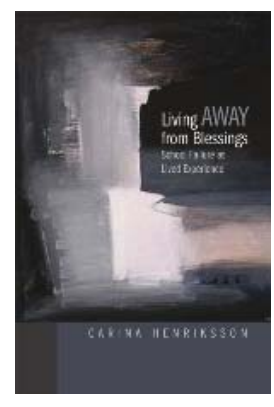

Phenomenology offers educational inquiry the possibility, and the often painful task, of articulating our actual lives as teachers. Reading Carina Henriksson's research on students' lived experiences of school failure challenges educators to re-consider what we think children experience in the classroom by truly orienting ourselves to the child's actual experience. Through thematic analysis of students' narratives of moments of failure in the classroom, the complex, nuanced, contingent, and often difficult lived phenomena of classroom life emerges as a counterpoint to the institutionalized forms of administrative and managerial accountability that seeks to dominate North American classrooms today. Henriksson's book, Living Away From Blessings: School Failure as Lived Experience, affirms that too many students' lives are driven by disturbing images of success and failure, of fear, of shame, of intimidation, and a deep and lasting sense of being labeled and marginalized in school settings that promote boredom and ennui. Yet, in a real way, the bad news turns out to be good news. This study reminds us of the way in which phenomenological insight "embraces the world as we live it, but in the process invites us to change the way we live” (Pinar, 1995, p. 413). Henriksson opens the reader to the possibility of changing classroom experiences for children by re-orienting how we stand in relation to children. She writes,

Teachers need to embrace that they are capable of deciding what is best for a particular child, that they are capable of tactful acts in the classroom. The proficiency to do so comes from spending time with children, from listening to them and from taking an interest in what goes on in children's lives. (p. 153)

The children's descriptions of lived experiences of failure at the center of this book provide an opportunity to deepen a sense of the ethical relationship teachers and students share and an opportunity to cultivate an orientation of tact and thoughtfulness in the pedagogical situation. 
Henriksson's book works on different levels. It is deeply dialogical: young people, who find themselves in juvenile institutions - marginalized, angry and cynical-share the narratives of the tumult and difficulties of their unique life experiences. Students, like Cathy and Ken, offer heartrending accounts of experiences of school failure. They allow their unique voices to be heard and echo voices of other children for whom we, as educators, may have been responsible. Their voices call and confront me with my own connection to and implication in a child's experience of failure. Who I am and how I live my life with children looms large in reading Living Away From Blessings. I am reminded of Heidegger's assertion that phenomenology “never makes things easier, but only more difficult” (as quoted in van Manen, 2007, p. 13). My patience, tolerances, biases, presumptions and deeply held beliefs are disrupted in my attempt to understand the child's experience of failure. Kelly, another research participant, says that her chronic absenteeism was, paradoxically, a call to be noticed in her absence. She felt teachers and administrators did not heed her call.

I used to sit on the lawn outside the school building but no one asked why I was not in class. They only called my parents a few times in the beginning when I started to misbehave. They gave up so easily - they gave up too easily. (p. 112)

The all too familiar problem of student absenteeism is re-framed in a manner that suddenly implicates me, challenges me, and makes an imperative, Levinasian claim on me. As with many of the students' lived experience descriptions I am struck by something that on the surface may seem a familiar classroom experience, yet for all its incidental character, arouses new and rich understandings of things already understood.

Henriksson's research points to the value of a phenomenological orientation to open our lives as practitioners to the infinite possibilities for creating meaningful, caring, pedagogical relations with the children in our charge. Unfortunately, classrooms are becoming openly hostile places for more children, as curricula are fragmented, standardized, and students and teachers are held accountable through the use of performance indicators designed to intimidate and control. The result is the emergence of teacher identities, especially in high schools, that reflect a managerial approach to learning. Teachers are becoming facilitators of learning outcomes rather than adults who stand in a deeply trusting pedagogical relation with children. Ironically, many children are in need of a trusting adult mentor and guide, now, as no time in the past. Consumerism fueled by pervasive and sophisticated media manipulation pressures parents to work more, longer and farther afield, depriving children of a stable home and relegating them to the care of strangers in often crowded daycare. There is a marked rise in eating disorders and obesity as children spend hours inside in the company of television, video and computer. The lack of connection to people, community and place is having a profound effect on children. In the United States, "an estimated five million children take at least one psychiatric drug" (Norberg-Hodge, 2003, p. 11). Every year this number grows. More children arrive at school unprepared for the expectations of the classroom. In the absence of answers and in the face of increasingly difficult questions about what kind of education students deserve, we must continue to live these questions out, making our lives worthy of what Barry Lopez (1986) calls a "leaning into the light” (p. 413). 


\section{Failing Schools}

Henriksson reveals the classroom to be an incubator of deeply felt experiences of failure. As a unifying experiential theme, the notion of failure is as varied and unique as the young people who offer an understanding of school failure as lived experience. The list of experiences is long and painful and includes, but is not limited to, experiences of failure to meet the requirements of the curriculum, to learn to read and write and solve math problems; failure to fit in, to find a safe and welcoming place; failure to get along with others and with teachers; failure to comply with school rules, to attend school regularly, to be prepared to learn and participate; failure to take responsibility for one's own success and failure. However, as the author points out, the students' written anecdotes, narratives and responses during interviews reveal that the students interpreted the concept of failure as school failure, and not as personal failure, as in cognitive, academic or behavioural struggle to meet teacher, curricular or school expectations, benchmarks or standards. It was the experience of personal failure that the author had hoped would emerge in the data. However, this was not to be the case. In many responses, the students recount, in great detail, their experience of the school's failure to provide a safe, caring, nurturing environment in which they can grow, learn and develop their unique talents and interests. The result is a rather bleak indictment of the classroom experience for students who feel their schools and teachers have failed them. In this sense, the word "fail" carries with it the idea of "not rendering the due or expected service or aid; to disappoint, to give no help to; to withhold help from” (OED, 2002, p. 666). To add insult to injury, the cruel paradox is that the child is cast as a failure and subject to deep and lasting shame in classrooms and schools in which teachers and administrators have, according to the students, essentially abrogated their pedagogical duty. Henriksson quotes Dante's insignia on the gates of hell, “Abandon all hope ye who enter here,” to capture the dread with which some children enter the classroom. This becomes less hyperbolic when close attention is given to the students' descriptions of lived experiences. John says,

My teachers never offered me the help I needed, the help they were supposed to give me. Only the most gifted children got their attention and support...I stopped asking for help, it was no use. Somehow my teachers made my failure into their personal failure... What right do teachers have to turn my failure into their failure and then have the nerve to hold it against me? Do they ever consider that they carry the future of the child in their hands? So much depends on how well you do in school and I think teachers should bear this mind. (p. 98)

John expresses his solitary struggle to receive help from the people he understands as responsible for him. A teacher may respond to John's criticism by countering that he does care for John, that there are many others in the class who also need his assistance, that there is only so much time in a class. However, as van Manen reminds us in the foreword of this book, it matters not that we, as educators, say that we care; the child's experience of teachers and classrooms as caring, affirming people and places is what really matters. 


\section{It is a Shame}

John's account, as is true of many others in Living Away From Blessings, reveals a sense of loneliness and alienation. Despite the sociality and interactive nature of group instruction that characterizes the education of children, I was struck by the recurring sense of isolation and the deep shame attached to that isolation. Firstly, Henriksson's informants are students who, for myriad reasons, including criminality, drug abuse and mental illness, are confined and marginalized within the juvenile justice system as "inmates" (p. 6). These troubled youth and their troubling words echo J.H. van den Berg's assertion that psychopathology is at bottom the "science of loneliness" (quoted in Fisher, 2002, p. 78). So many of the student's lived experience descriptions are the painful memories of being shunned, rejected, ignored, misunderstood, and overlooked. Only a being who essentially belongs with others can suffer from isolation. When hurt by others, our basic social self is damaged. As is obvious through the voices in Henriksson's book, our trust in relationships, our faith in the nature of things, our belief in the goodness of others and the safety of the world - all are weakened. It is this experience that contributes to the author's theme of shame as it relates to school failure. Matt's experience encapsulates this profound feeling of isolation, disappointment and shame; he admits to "stepping back" and letting his friends monopolize the teacher's attention. Matt is upset however, when the teachers admonish him for not doing his best. He interprets the teachers' motivations as trying to motivate him to do better, "but it made me feel even more stupid." Matt expresses his disillusionment and disappointment with those he feels are responsible for his learning and well-being.

Even the headmaster let me down. It was all just talk. She made so many promises, and we scheduled meetings but she never showed up. I tried to keep my end of the bargain, but in the end she gave me the finger... I gave up and stayed away from school for a couple of weeks. Of course, they kicked me out. (p. 106)

In the section titled, "The Shameful Space," the author draws out the theme of shame from an experiential description of an embarrassing moment and the teacher's lack of tact and thoughtfulness to ameliorate the student's public shaming. Conversely, the teacher uses the shaming as a punitive measure, as an instrument of control. Shame is the experience of having some part of ourselves, some action, movement of ours disapproved of, ridiculed, refused or unacknowledged. We are exposed as "defective" or unworthy, not part of the group. When we feel shame we avert our eyes, hang our heads, shrink, disappear, and hide. Cathy writes of her public shaming, "I leave the classroom with sad steps and tears oozing down my cheeks and decide there and then never to attend another English class." There is a break in the connection between the child and her surroundings, with the others who refuse her. Wherever there is a disconnect in a social environment we can expect shame. In classrooms ruled by individualism, competitiveness, by the fear and intimidation intrinsic in being measured, judged and ranked, shame in endemic. Living Away from Blessings allows the voices of children, those most deeply 
affected by our culture's essential maladies, to punch through and awaken our conscience to the destruction of experience that too often characterizes our children's classrooms.

\section{Feeling out of Place}

A reader of Henriksson's research into the lived experience of school failure will be struck by the predominant role of place as a pervasive dimension of the experience of failure. Henriksson references Heidegger's concept of Befindlichkeit, the moodwise situatedness of being: “Heidegger's concept connotes how we sense ourselves in situations, but a mood is just not internal. It relates to living in this world, to how we understand our place in the world" (p. 130). Each theme that Henriksson develops, as an eidos of the experience of school failure, is tied deeply to an experiential dimension of how we find ourselves in place. Place figures greatly in most student experiences of failure. The notion of place is obvious in many of Henriksson's chapter titles and headings that seek to express and uncover the lived meaning of school failure. Such headings include: Make Yourself at Home!, The Shameful Space, The Void of Marginalization, (Be) longing, Privacy and Secrecy, and Place of Abode. Henriksson's research is important as it demonstrates place at the center of a child's experience of school. Unfortunately, place as an experiential and critical construct does not figure prominently in educational discourse. Living Away from Blessings offers structures of experience of place that point to a deeper understanding of a child's experience in school.

When phenomenologically interpreted, place becomes more than a mere physical container, but reflects instead the ontological primacy of dwelling. When we thoughtfully consider what it means to dwell in or in-habit a place as embodied beings, we are challenged to think about classrooms and schools as more than the mere physical containers they have become, but as spaces in which ensouled beings live in a dynamic, reciprocal relation with their environments. Henriksson's research helps disrupt and overcome the false dualism between mind and place. To exist is to exist somewhere, in some place. In the words of Edward Casey (1993), "to exist at all...is to have a place - to be implaced...the point is that place, by virtue of its unencompassability by anything other than itself, is at once the limit, the condition of all that exists” (pp. 17 -19).

Henriksson's discussion of the experience of student boredom is particularly compelling for the classroom teacher as it is tied directly to place, to our situatedness as embodied beings:

If I were to single out one notion which almost all students to whom I have talked eventually mention, it would be boredom....Does school as a societal institution cause boredom? Is boredom perhaps a feeling that arises in the encounter between child and school? (pp.128-129)

As is true with many other dimensions of the experience of school failure, understanding student boredom more deeply inevitably leads us into the complexities and intertwining of place and time. The tedium of routinized classes endured by disengaged students inextricably links time and place. Pedagogues must be mindful that the environment that surrounds us is not simply 
outside our bodies, anymore than our bodies are separate from their surroundings. Ecological thinking reminds us, as embodied beings, of the essential porosity of our relationship with the world. Our embodied existence is essentially a spatializing and temporalizing activity of beingin-the-world and a fundamental opening up to the situation within which we find ourselves. A phenomenological discussion of boredom as school failure unlocks the possibilities for creating formative relations between being and acting, between how we plan, design and build classroom spaces and allocate class time to allow for the engagement of teachers and students in places that affirm who we are as human beings.

\section{Research as Transformation}

Henriksson's Living Away From Blessings also works well as a narrative of the transformative possibilities of the phenomenological research process. Van Manen (1997) writes,

From a phenomenological point of view... the act of researching - questioning theorizing is the intentional act of attaching ourselves to the world, to become more fully part of it, or better, to become the world.... Then research is a caring act; we want to know that which is most essential to our being. (p. 5)

Henriksson as researcher/writer is ever present in the narrative illustrating the contingent and creative possibilities that open up when one turns oneself over to the interpretive process. As I encountered the lived experience descriptions from students I was immediately confronted by my own preunderstandings: What I expected to get was not what students were willing to give and that, of course, unnerved me. Was I not heading for a school failure (p. 29)?

Later Henriksson admits her trepidation at spending time with students who may be addicted to drugs, have violent histories, criminal pasts or who may even be psychotic. "The relationship between researcher and informant became somewhat of an ethical dilemma. I realized I felt uncomfortable with the thought of meeting students in the juvenile institutions” (p. 49). Living Away From Blessings offers a worthwhile account for any graduate student about to embark on a human science research project. As is often the case and as this book demonstrates, multiple pedagogical realities emerge out of the interpretation of the data, both the students' and the researcher's. For the researcher, as for the reader, the hermeneutic conversation, the reflection on and engagement with the data, is transformative and deepens a sense of interconnectedness with children struggling with the many facets of failure in school.

The student lived experience descriptions are compelling and often raw in their difficulty and ambiguity within the relational interplays that characterize the lifeworld of the classroom. The teacher and student matrix is the nexus out of which meaning may emerge. The author states, "Their (the teachers') written and oral experiential accounts offered me a more profound understanding of my research question” (p. 39). Unfortunately, very few of these teacher accounts actually make it into the book. I would have liked to read more of the teachers' lived experience descriptions and the author's hermeneutic reflections on these descriptions to better understand the teacher-student relational nexus and the living character of this relation in all its 
contingency, messiness and difficulty. Understanding the experience of failure in the classroom is something everyone in the classroom is already involved in-teacher and student both. To hear more of the teacher's voice would enrich the conversation.

So often the language of education is the language of the technical, rationalist, and positivistic. The current preoccupation with standardized testing that leads to scripted curricula designed to mitigate the influence of the troublesome "variable" of the classroom teacher represents a way of being in the world. However, when we are out in the world, in schools and classrooms filled with students and their teachers, we find this "high status" language falls away; it is a discourse that shrinks before the clear light of day and the world mapped by its discourse is rendered a hegemonic fiction, a consensual illusion. Henriksson's language is vital and particularizing. It draws deeply on the fact that the world I meet outside my door is unpredictable and contingent; it defies containment in its myriad encounters and little epiphanies, much like the minds, spirits, and wills of the students I meet in the classroom. For example, Henriksson's discussion of school rules and norms, particularly the significance of the "cap question"- the rule concerning the wearing of headgear in classrooms-is a perennial source of debate and contesting views. Henriksson seeks to illumine the subject and cast the question of the appropriateness of hats and caps in the classroom by turning to Sartre's metaphor of "the look" (p. 96) and Levinas' speaking “eye” (p. 96). Phenomenology does not offer a "how to" quick fix for classroom management problems; through metaphor, the taken-for-granted is laid bare and that which is most often silent may be heard. Henriksson demonstrates that phenomenology requires a sensitivity to language, to its subtleties, and its undertones. It is the everyday, the taken-for-granted, the pre-reflective life that is the concern of phenomenology. Living Away From Blessings chronicles experiential accounts collected from students and opens up the experiences, allowing something to be revealed in language that is at once evocative, powerful and sensitive.

Living Away From Blessings provides educators with a sensitive account of one researcher's attempt to make interpretive sense of children's experiences of failure in school. It is an important contribution to education research as it provides a space in which pedagogical thoughtfulness, sensitivity and understanding is presented as means to enhance and protect the child and nurture growth and learning. Henriksson challenges the technical, rationalist mindset deluded by the belief that education can be improved simply by designing better curricula, implementing better instructional techniques, introducing the latest technology, or tightening up classroom management protocols. This book also demonstrates that phenomenology is a disciplined and rigorous effort to understand lived experience and in doing so, it accepts - rather than controls - the messiness, complexity and contingency of everyday life and human experience. Living Away From Blessings discloses what it means to experience school as failure as it evokes a sensitive, thoughtful, pedagogical orientation as counterpoint to the instrumental rationalism of a managerial view of classrooms, teachers and children so pervasive in North American education today. 


\section{References}

Casey, E. (1993). Getting back into place: Toward a renewed understanding of the place-world. Bloomington and Indianapolis: Indiana University Press.

Fisher, A. (2002). Radical ecopsychology: Psychology in the service of life. Albany, New York: State University of New York.

Lopez, B. (1986). Arctic dreams: Imagination and desire in a northern landscape. New York: Vintage.

Norberg - Hodge, H. (2003). Waking from the corporate American dream. Orion 22 (6), 11.

Oxford English dictionary (compact) $2^{\text {nd }}$ ed. (2002). Oxford: Oxford University Press.

Pinar, W., Reynolds, W., Slattery, P., Taubman, P. (2002). Understanding curriculum: An introduction to the study of historical and contemporary curriculum discourses. New York: Peter Lang.

van Manen, M. (1997). Researching lived experience: Human science for an action sensitive pedagogy. London, Ontario: Althouse Press.

van Manen, M. (2007). Phenomenology of practice. Phenomenology \& Practice 1 (1): 13. 